\title{
Complutum
}

ISSN: 1131-6993

\section{El espacio ordenado. Paisaje, orientaciones y astronomía en los albores de la época ibérica en Mazaleón (Teruel) ${ }^{1}$}

\author{
César Esteban²; Luis Fatás Fernández ${ }^{3}$; Francisco Romeo Marugán ${ }^{4}$; Fernando Chavarría Forés ${ }^{5}$
}

Recibido: 18/01/2021 / Aceptado: 28/04/2021

Resumen. Presentamos un estudio arqueoastronómico de la denominada habitación 2 del poblado preibérico de San Cristóbal de Mazaleón (siglos VII-VI a.C.) y de varios túmulos de la necrópolis contemporánea asociada. La habitación 2 presenta una orientación ajustada a los ejes cardinales y un marcador del orto solar en fechas alrededor de los equinoccios sobre la parte central del cerro que domina el horizonte oriental, unas características comunes en varios santuarios ibéricos del sureste. Estos resultados, junto a la tipología del material arqueológico encontrado en su interior, nos llevan a proponer su uso como espacio sacro, donde se llevarían a cabo ritos relacionados con la fertilidad alrededor de los equinoccios, o como escenario de ceremonias de redistribución y negociación social. La comparación de la cronología del poblado con la de otros santuarios protohistóricos con elementos arqueoastronómicos similares indica que este espacio es, hasta la fecha, el más temprano de todos ellos. Los túmulos de la necrópolis muestran un patrón de orientaciones hacia el oeste-suroeste bien definido, coincidente con el que muestra la mayoría de los túmulos protohistóricos de otras necrópolis del Bajo Aragón y quizás relacionado con los ocasos solares.

Palabras clave: Arqueoastronomía, santuarios, túmulos, necrópolis, Cultura Ibérica, protohistoria.

\section{[en] The ordered space. Landscape, orientations and astronomy at the dawn of iberian epoch in Mazaleón (Teruel)}

\begin{abstract}
We present an archaeoastronomical study of the so-called Room 2 of the pre-Iberian settlement of San Cristóbal de Mazaleón (7th-6th centuries BC) and of several burial mounds from its associated necropolis. Room 2 is oriented quite precisely along the cardinal axes and shows a marker of the sunrise around the equinoxes on the central part of the hill that dominates the eastern horizon, a common feature in several Iberian sanctuaries in the southeast of the Iberian Peninsula. These results, together with the typology of the archaeological material found inside Room 2, lead us to propose its use as a sacred space, where fertility-related rites would be carried out around the equinoxes, or as the place for redistribution and social negotiation ceremonies. Comparison of the chronology of the site with those of other Protohistoric sanctuaries with similar archaeoastronomical findings suggests that this space is, by now, the earliest of them all. The burial mounds of the necropolis show a well-defined pattern of orientations towards the westsouthwest, coinciding with that shown by most of the Protohistoric burial mounds of other necropolises of Bajo Aragon and perhaps related to the sunset.
\end{abstract}

Keywords: Archaeoastronomy, Sanctuaries, Tumuli, Necropolises, Iberian Culture, Protohistory.

1 Este trabajo ha sido posible gracias al proyecto "Arqueoastronomía" (P/309307) del Instituto de Astrofísica de Canarias. Este proyecto está financiado por fondos transferidos desde el Ministerio de Ciencia, Innovación y Universidades, con cargo a los Presupuestos Generales del Estado y con fondos transferidos por la Consejería de Economía, Industria, Comercio y Conocimiento, de los Presupuestos Generales de la Comunidad Autónoma de Canarias.

2 Instituto de Astrofísica de Canarias. C/Vía Láctea S/N. 38200 San Cristóbal de la Laguna, Santa Cruz de Tenerife. Departamento de Astrofísica. Universidad de La Laguna.

E-mail: cel@1l.iac

ORCID: http://orcid.org/0000-0002-5247-5943

3 Gobierno de Aragón. Dirección General de Cultura y Patrimonio. Avda. Ranillas 5D. 50008 Zaragoza.

E-mail:1fatas@aragon.es

ORCID: http://orcid.org/ 0000-0001-9220-7559

4 Gobierno de Aragón. Dirección General de Cultura y Patrimonio. Avda. Ranillas 5D. 50008 Zaragoza.

E-mail: fromeo@aragon.es

ORCID: http://orcid.org/0000-0003-2391-9418

$5 \quad$ C/Isabel II, $162 \mathrm{n}-1^{\mathrm{a}}$. 43520 Roquetes, Tarragona

E-mail: tyrichae@hotmail.com

ORCID: https://orcid.org/0000-0002-2069-4068 
Sumario: 1. El poblado y la necrópolis de San Cristóbal de Mazaleón. 2. Método de trabajo y obtención de datos. 3. Resultados. 3.1. La habitación 2 del poblado. 3.2. Túmulos de la necrópolis de San Cristóbal. 4. Discusión. 4.1. La orientación de la habitación 2 y el marcador equinoccial. 4.2. La orientación de los túmulos de la necrópolis de San Cristóbal. 5. Conclusiones. 6. Bibliografía.

Cómo citar: Esteban, C.; Fatás Fernández, L.; Romeo Marugán, F.; Chavarría Forés, F. (2021): El espacio ordenado. Paisaje, orientaciones y astronomía en los albores de la época ibérica en Mazaleón (Teruel). Complutum, 32(1): 97-115.

\section{El poblado y la necrópolis de San Cristóbal de Mazaleón}

El poblado y la necrópolis de San Cristóbal de Mazaleón son yacimientos clásicos dentro de la arqueología protohistórica peninsular gracias a los trabajos de excavación desarrollados hace poco más de un siglo por Bosch Gimpera dentro del ambicioso programa que llevó a cabo al frente del Servei d'Arqueologia del Institut d'Estudis Catalans (Bosch Gimpera 1913-14, 1915-1920). Gran parte de estos trabajos se incluyeron desde ese momento en la literatura científica. No obstante, y a pesar de las excavaciones de Tomás Maigí en el poblado y de su sistematización del mundo de las necrópolis de cista excéntrica (Tomás 1959, 1960; Atrián 1961), hay que esperar a las revisiones puntuales de materiales impor- tados por parte de Sanmartí para completar el conocimiento -superficial- de este poblado y su necrópolis. Serán los (re)estudios de las necrópolis bajoaragonesas de Rafel (2003) y de los poblados excavados por el Institut de Fatás (2016), además de la excavación en alguna de las zonas aún sin agotar, los que terminen de reevaluar y contextualizar el conjunto del poblado y necrópolis de San Cristóbal dentro del mundo protohistórico peninsular.

El poblado se ubica en un cerro localizado en un meandro del río Matarraña (Fig. 1), otorgándole una posición estratégica con un gran control visual tanto aguas arriba como aguas abajo. Su planta ha sido definida por algún autor como axial (ver Fig. 2), si bien las actuaciones realizadas durante la primera década del siglo XXI parecen apuntar a una mayor complejidad.

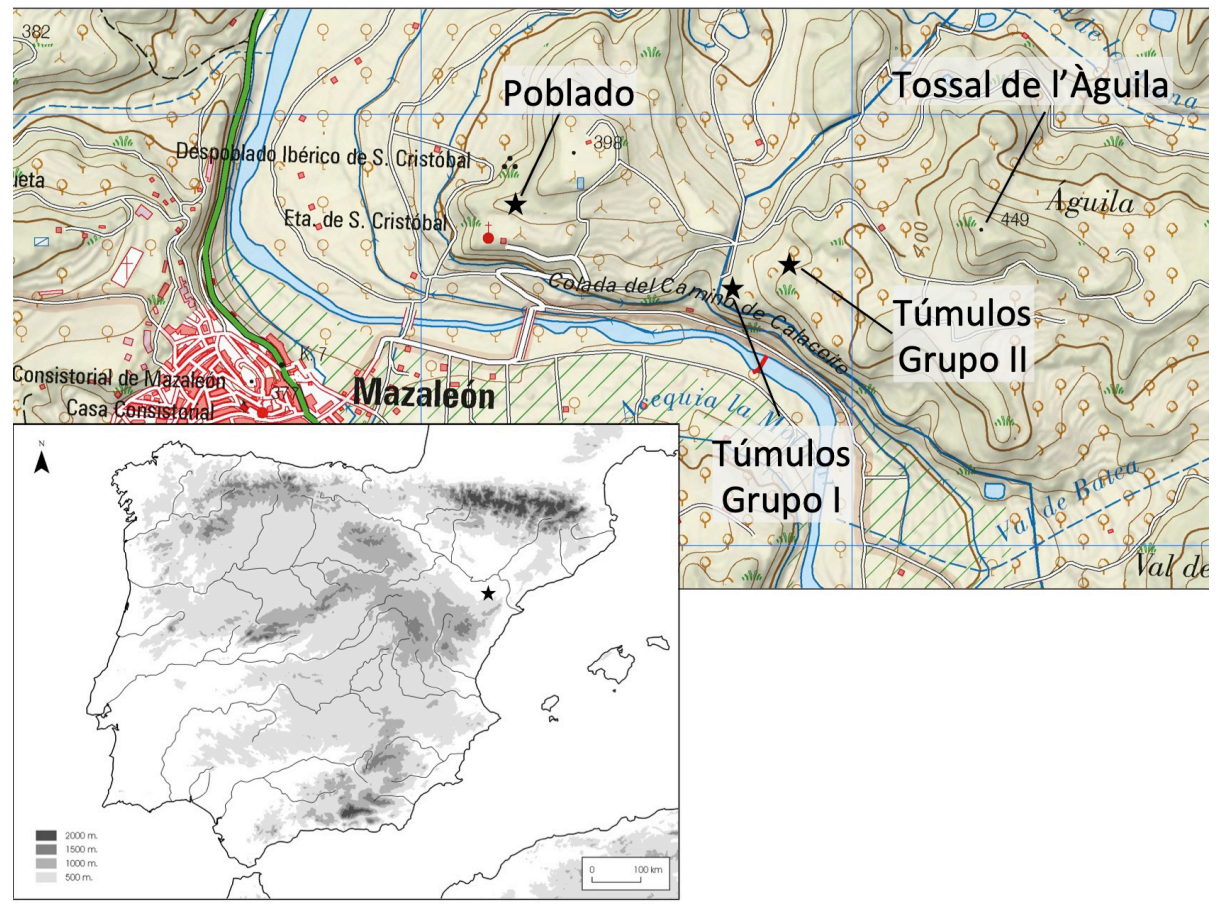

Figura 1: Localización del municipio de San Cristóbal de Mazaleón sobre un mapa de la península ibérica (recuadro inferior izquierda) y del poblado protohistórico, los dos grupos de túmulos y del Tossal de l’Àguila sobre el plano 1:25.000, hoja 0469-4, del Instituto Geográfico Nacional. 
Las traseras de las casas conforman probablemente la muralla hacia el lado norte (Fig. 2). En el extremo oriental se aprecia la existencia de una construcción circular ataludada que algunos autores interpretan como una torre y otros como estructuras de almacenaje (Bea et al. 2012: 64-66), que se vincularía al cierre del poblado. El lado oeste resulta más complejo de interpretar. La aparición de un muro rectilíneo no conservado y que grafía Bosch Gimpera en sus planos, conecta la zona "nuclear" con una serie de estructuras articuladas en torno a un muro de potencia considerable y que sirve de cierre a una pequeña área que nos ha llevado a plantear por este motivo que estaría más fortificada y quizás se pueda vincular dentro del surgimiento de una arquitectura de prestigio con estructuras de poder (Bea et al. 2012: 65). Aunque tradicionalmente no se planteaba ninguna ocupación hacia el sur, las excavaciones antes referidas han permitido constatar, a unos $75 \mathrm{~m}$ lineales de la zona conocida, estructuras con materiales protohistóricos contemporáneos al resto del poblado.

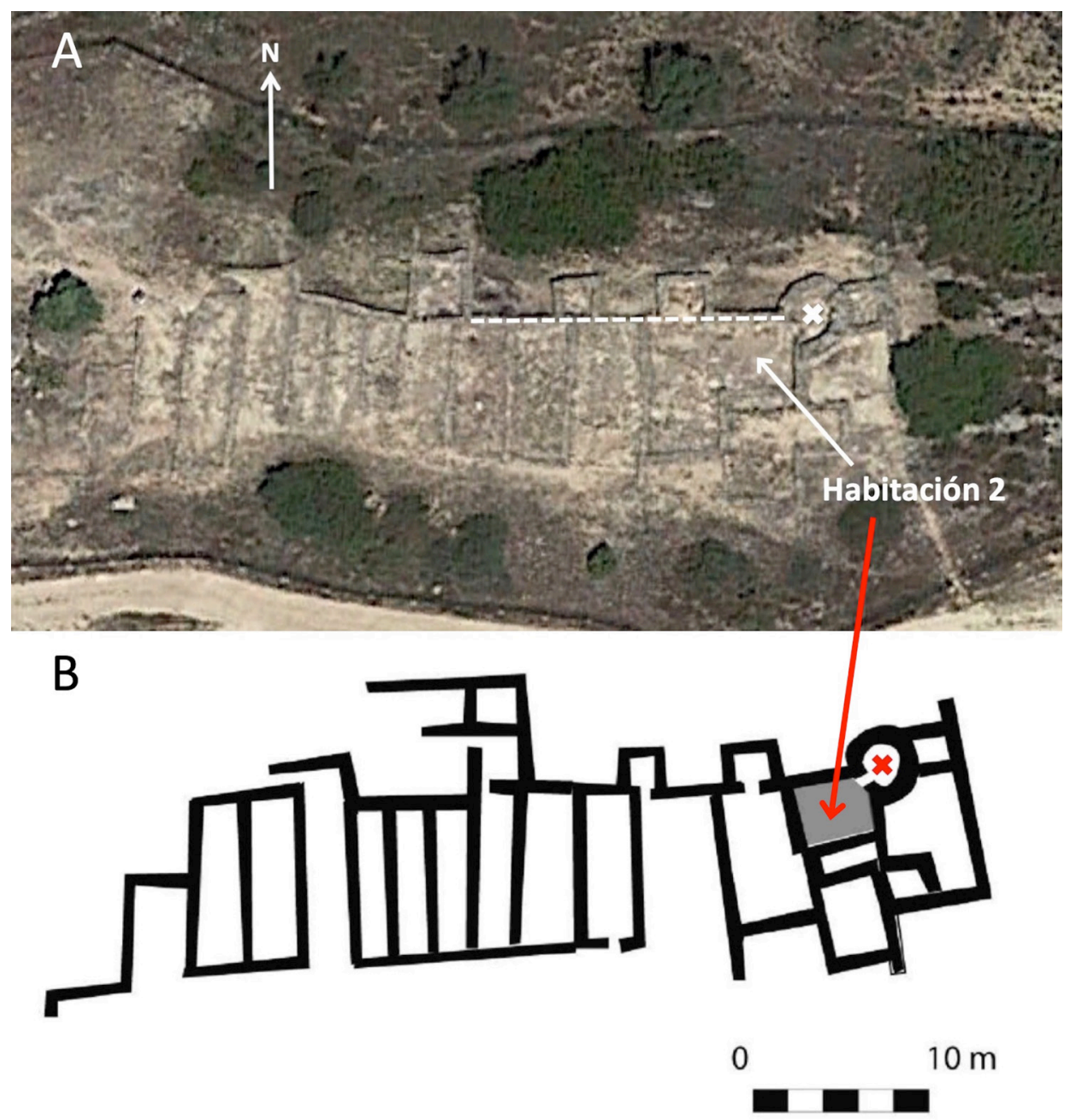

Figura 2: A: Fotografía satelital (obtenida de Google Earth Pro) de la zona oriental del poblado protohistórico de San Cristóbal de Mazaléon. Se indica la posición de la habitación 2, el muro norte (línea discontinua) y el punto donde se colocó el teodolito para la toma de medidas (señalada por una cruz), en el centro del espacio circular. B: Planta simplificada de la zona central del poblado donde también se indica la posición de la habitación 2 (área gris) y la posición del teodolito (cruz roja).

La cronología del yacimiento, que con los datos disponibles de la interpretación de los materiales y los diferentes sondeos parecen corresponder a una única fase de ocupación, arrancan en la segunda parte del siglo VII a.C., con un final acompañado de una destrucción 
del asentamiento (niveles de cenizas caída de adobes,...) en la primera mitad del siglo VI a.C. (Fatás 2007: 179) con paralelos en su cultura material con muchos yacimientos contemporáneos del Bajo Aragón y la Terra Alta y la presencia de importaciones mediterráneas, imitaciones de éstas y de las primeras cerámicas torneadas del litoral típicas de estos horizontes preibéricos o protoibéricos.

La revisión de materiales permitió, gracias a la conservación de los inventarios de las excavaciones antiguas y las anotaciones presentes en las fotografías conservadas en el Museu d'Arqueologia de Catalunya de Barcelona, identificar uno de los espacios más particulares del poblado: la habitación 2 (Fatás 20042005). Este recinto destaca con respecto al resto por la cantidad y calidad de los materiales encontrados en su interior y por la presencia de una columna de madera, cubierta por un revestimiento de barro decorado con motivos geométricos, como elemento central. La habitación 2 está ubicada en la zona oriental del poblado y por ella se accedía a la posible torre o espacio de almacenaje circular del que hablábamos anteriormente. En cuanto a los materiales, sin entrar en detalles ${ }^{6}$ se puede mencionar la aparición de una mesa o elemento similar portátil, un vaso de tipo anforoide de origen fenicio, varias imitaciones de materiales importados, la presencia iconográfica de aves en al menos dos cerámicas diferentes y huesos de suido y cánido. Esta suma de elementos, nos llevó a plantear la presencia de un espacio que definimos en su momento como diferencial y que sería escenario de los rituales conviviales donde se empezaba a plasmar la diferenciación social dentro de una incipiente jerarquización que llevaría al Ibérico Antiguo.

En cuanto a la necrópolis, su conocimiento también se remonta a las primeras décadas del siglo pasado, con las mencionadas campañas de excavación del Institut d'Estudis Catalans. En ese sentido, resulta fundamental el reestudio de los materiales que hizo Rafel (2003), donde completó la superficial visión que se tenía del conjunto de necrópolis excavadas por Bosch y ordenó toda la información que proporcionaban los inventarios y diarios conservados en el Museo.

Su ubicación es semejante a la de otras necrópolis de esta época. Consta de unos 20 tú- mulos y se sitúa en torno al poblado en unas cotas ligeramente inferiores a las del poblado. Se agrupan, según señala Tomás $(1959,1960)$, en tres grupos de dos y dos grupos de tres, quedando los ocho restantes aislados. Su cronología resulta contemporánea a la del poblado, como apuntan elementos como una fíbula de doble resorte, un plato a mano de engobe rojo que Rafel interpreta como de influencias fenicias, un vaso pintado o algunas otras piezas recuperadas (Rafel 2003: 31-38).

\section{Método de trabajo y obtención de datos}

El interés arqueoastronómico del poblado de San Cristóbal de Mazaleón surgió en 2010, cuando uno de los autores del presente trabajo (F. Chavarría Forés) visitó el yacimiento y comprobó que el muro norte del extremo oriental del complejo se encontraba orientado hacia un cerro cercano (Tossal de l'Àguila) donde podría producirse el orto solar en los equinoccios.

El 29 de mayo de 2019 se realizaron medidas arqueoastronómicas en el poblado y en dos de los grupos de túmulos de la necrópolis asociada descrita en la sección anterior. El instrumental utilizado fue un teodolito Settop TEO-3, una brújula de precisión, un receptor GPS de navegación y una cámara fotográfica digital. La escala mínima de graduación del teodolito es de $0,05^{\circ}$ centesimales en ambos ejes, que corresponde a $0,045^{\circ}$ sexagesimales. En el caso de la brújula, la escala mínima de medida es de $1^{\circ}$ sexagesimal. Con este último instrumento se midió el ángulo horizontal respecto al norte magnético de varios muros del extremo noroeste del poblado y de las aberturas de acceso de los túmulos. El teodolito se situó en el centro de la estancia circular situada en el extremo noreste del poblado (ver figuras 2 y 3 ) y, desde allí, se midió el ángulo horizontal y la altura sobre el horizonte $(h)$ de un cierto número de cotas, incluyendo puntos a lo largo del perfil del Tossal de l'Àguila así como diversos rasgos topográficos destacables del horizonte, como picos de montaña o intersecciones entre laderas de montañas contiguas. Cada ángulo horizontal medido con el teodolito se transformó a $\operatorname{acimut}^{7}(A)$ referido al norte geográfico mediante varias medidas de la posición

Para más información vid.: Fatás (2004-2005)

Acimut: ángulo horizontal respecto al norte geográfico 
del centro del disco solar cronometradas con el GPS, que también proporciona el Tiempo Universal preciso. La declinación magnética (diferencia angular entre el norte magnético y el geográfico) se determinó comparando los ángulos horizontales medidos con ambos instrumentos, brújula y teodolito, para un mismo conjunto de cotas. La declinación magnética es la magnitud que hay que sumar algebraicamente para transformar los ángulos horizontales medidos con la brújula a acimuts. Este parámetro solo se determinó en el poblado, por lo que hemos supuesto el mismo valor a la hora de corregir las medidas de orientación de los túmulos, pues debido a su escasa distancia y a la geología del terreno, no esperamos que existan alteraciones magnéticas que produzcan variaciones de la declinación magnética de un lugar a otro.

A partir del par de coordenadas $A$ y $h$ de los puntos del horizonte medidos con el teodolito o con la brújula y conocida la latitud, obtenida con el GPS, podemos calcular la declinación celeste $^{8}(\delta)$ del astro que tiene su orto u ocaso por dicho punto a través de una sencilla ecuación de transformación de coordenadas (ecuación 5 de Esteban y Moret 2006).

\section{Resultados}

\subsection{La habitación 2 del poblado}

Como se indica en las figuras 2 y 3 , el teodolito se situó en el interior de la estancia o espacio circular, Cambra circular, tal y como se la denomina en el material fotográfico de las excavaciones de Bosch Gimpera (Fatás 20042005). Se tomó especial cuidado en alinear el instrumento con el muro norte de la habitación 2, contigua a la estancia circular (también señalada en la Fig. 2) e interpretada como un espacio de carácter diferencial debido a los materiales singulares encontrados en su interior (Fatás 2004-2005, Sardá, Fatás y Graells 2010), como ya se comentó en la sección 1 .

Con la brújula de precisión se midió la orientación de los muros norte, sur y este (los que presentan un mejor estado de conservación) de la habitación 2, encontrando que son prácticamente ortogonales, presentando una orientación promedio, en sentido hacia el este, de $90.0^{\circ} \pm 1.5^{\circ}$, donde la incertidumbre asignada corresponde a la desviación estándar de los valores de $A$ proporcionados por los tres muros considerados (para el muro este se consideró la orientación de su perpendicular hacia el este). Como vemos, la orientación del espacio se ajusta perfectamente a los ejes cardinales. En la fotografía aérea del poblado (ver Fig. 2), se puede comprobar que el muro norte del espacio 2 se extiende a lo largo de unos $25 \mathrm{~m}$ hacia el oeste, formando parte del cerramiento de varios departamentos contiguos, siendo este muro el elemento arquitectónico del poblado que muestra una orientación más rectilínea y regular, sugiriendo que pudo tener un cierto protagonismo en el diseño del asentamiento. En la Fig. 3 podemos ver que el muro norte de la habitación 2 apunta hacia el Tossal de l'Àguila y muy cerca de donde se produce el orto solar en los equinoccios o en el punto mitad temporal entre solsticios (PMTS), ambos eventos señalados en la figura. El PMTS es una posición solar muy cercana a los equinoccios. El ingeniero escocés Alexander Thom, uno de los pioneros de la arqueoastronomía, denominó el PMTS como "equinoccio megalítico" debido a que, hacia ese punto, parecían orientarse ciertos monumentos megalíticos de las Islas Británicas (Thom 1967). Los dos PMTS que se producen en un año se encuentran justo a mitad del periodo de tiempo que transcurre entre los solsticios de verano e invierno y viceversa. No coinciden exactamente con los equinoccios debido a la forma elíptica de la órbita terrestre, lo que implica que la velocidad de la Tierra alrededor del Sol no sea constante. El primer PMTS del año se produce entre uno o dos días después del equinoccio de primavera y, el segundo, otros tantos días antes del equinoccio de otoño. La $\delta$ del Sol en esas fechas puede variar entre $+0,3^{\circ} \mathrm{y}+1^{\circ}$ (Ruggles 1997) en el momento del amanecer, por ese motivo el PMTS se indica con dos flechas (ambas indicando sus valores extremos) en la Fig. 3. El PMTS es un concepto mucho más intuitivo, práctico y mensurable que el de equinoccio astronómico que usamos en la actualidad, por lo que nos parece más verosímil que fuera el fenómeno de interés en las orien-

La declinación corresponde al ángulo sexagesimal entre un astro y el ecuador celeste medido a lo largo del círculo máximo que pasa por los polos celestes y dicho astro. Es una de las coordenadas ecuatoriales (junto con la ascensión recta) que se utilizan para localizar los astros sobre la esfera celeste, el rango de valores posibles varía de $+90^{\circ}$ a $-90^{\circ}$. 
taciones cercanas al punto cardinal este que apuntan hacia el orto solar en el mundo ibéri- co (ver Esteban 2016, 2017 para una discusión más extensa al respecto).
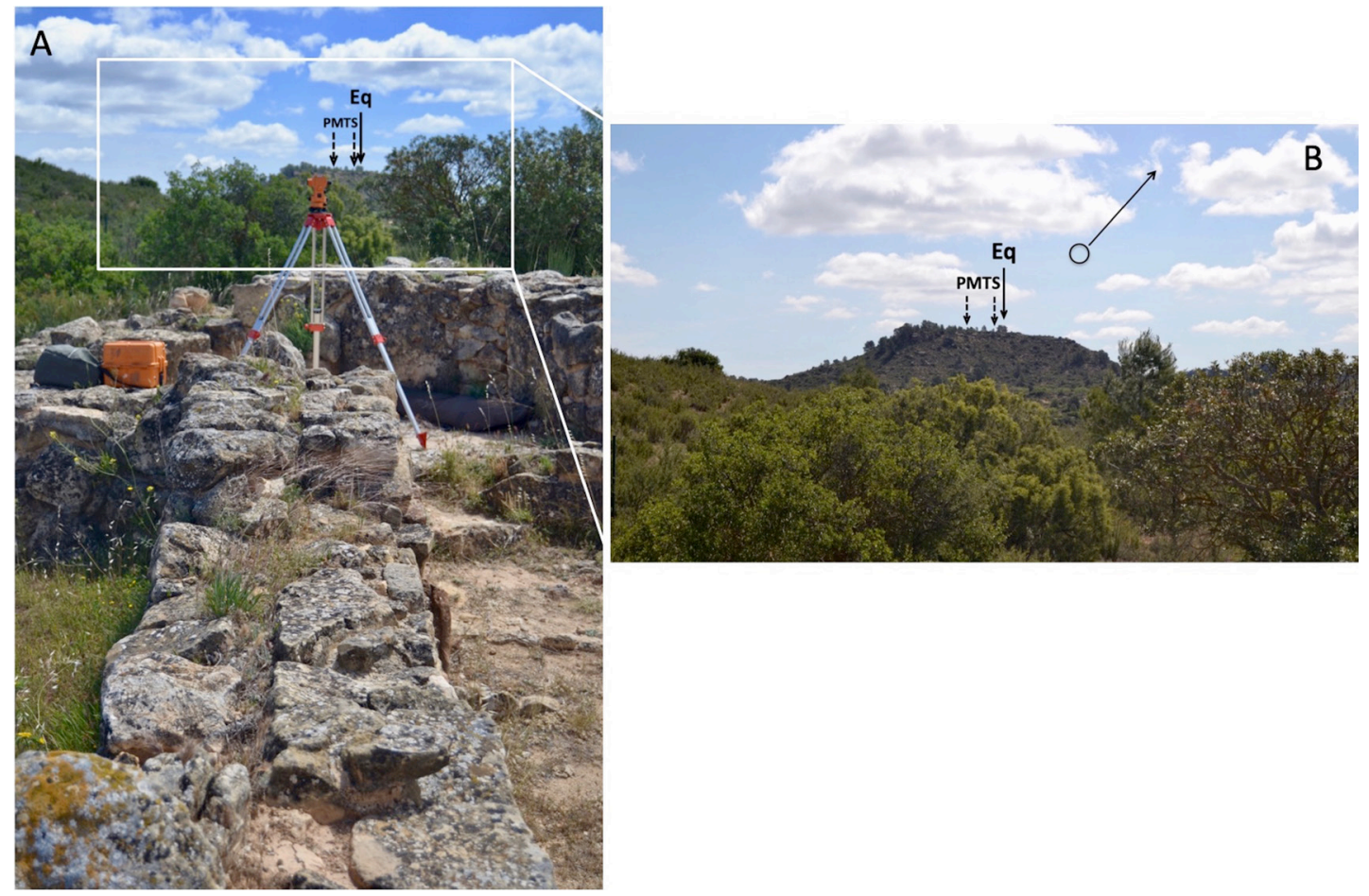

Figura 3: A: Vista parcial del horizonte oriental desde el muro norte de la habitación 2 del poblado protohistórico de San Cristóbal de Mazaleón. Se puede observar la posición donde se colocó el teodolito para la toma de medidas, en el interior del espacio circular. B: Ampliación del recuadro mostrado en (A) obtenido desde una posición más elevada con el fin de evitar la vegetación más cercana a las edificaciones. Se indican los puntos por donde se producen los ortos solares en el equinoccio (flecha continua) y los extremos por donde se producen dichos ortos en el punto medio temporal entre solsticios (PMTS, flechas discontinuas), todos ellos sobre el Tossal de l'Àguila. El círculo indica el tamaño angular del disco solar y la flecha oblicua la inclinación de su trayectoria mientras asciende en el cielo.

En la Fig. 4 podemos ver como el muro este de la habitación 2 apunta, en sentido sur, hacia una de las alturas del Tossal Gros, una elevación situada a unos $2 \mathrm{~km}$ de distancia. Aunque podría ser una simple coincidencia, no deja de ser un hecho sugerente que llevaría a pensar en la posibilidad de que dicha habitación no solo se encontrara orientada respecto a los ejes cardinales sino también respecto a elementos destacados de la topografía circundante. Otro hecho interesante es que el orto solar en el solsticio de invierno, la posición más meridional por donde podríamos ver aparecer el Sol a lo largo del año, se produce $^{9}$ (y se producía también en la época de fundación y uso del poblado, entre los siglos VII y VI a.C., Sanmartí-Grego 1979, Fatás 2007) sobre las estribaciones meridionales del Montsagre de Paüls, cadena montañosa con alturas entre 1000 y $1100 \mathrm{~m}$ y situada a unos $25 \mathrm{~km}$ de distancia (ver Fig. 5), uno de los elementos topográficos más lejanos visibles desde el emplazamiento, hecho que podría haber sido utilizado como marcador del solsticio de invierno mediante observaciones tanto desde la habitación 2 o la estancia circular como desde cualquier otro punto de la zona central del poblado.

La declinación del centro del disco solar en el solsticio de invierno en la actualidad es de unos $-23.4^{\circ}$ y de $-23.7^{\circ}$ en la mitad del primer milenio a.C., un desplazamiento del orden de medio diámetro solar. 


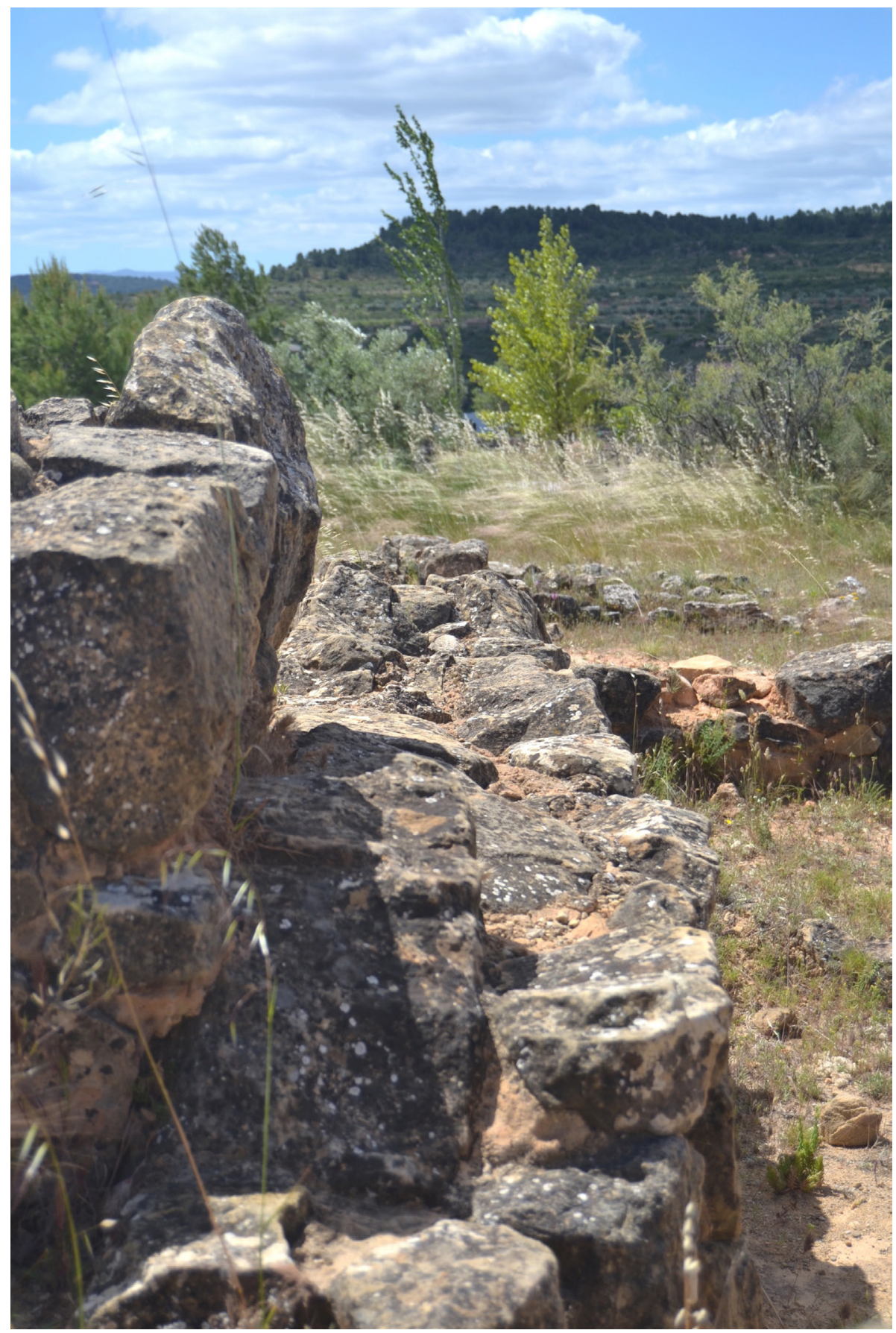

Figura 4: Vista parcial del horizonte sur desde el muro este de la habitación 2 del poblado protohistórico de San Cristóbal de Mazaleón. Se puede observar el alineamiento del muro hacia el Tossal Gros. 


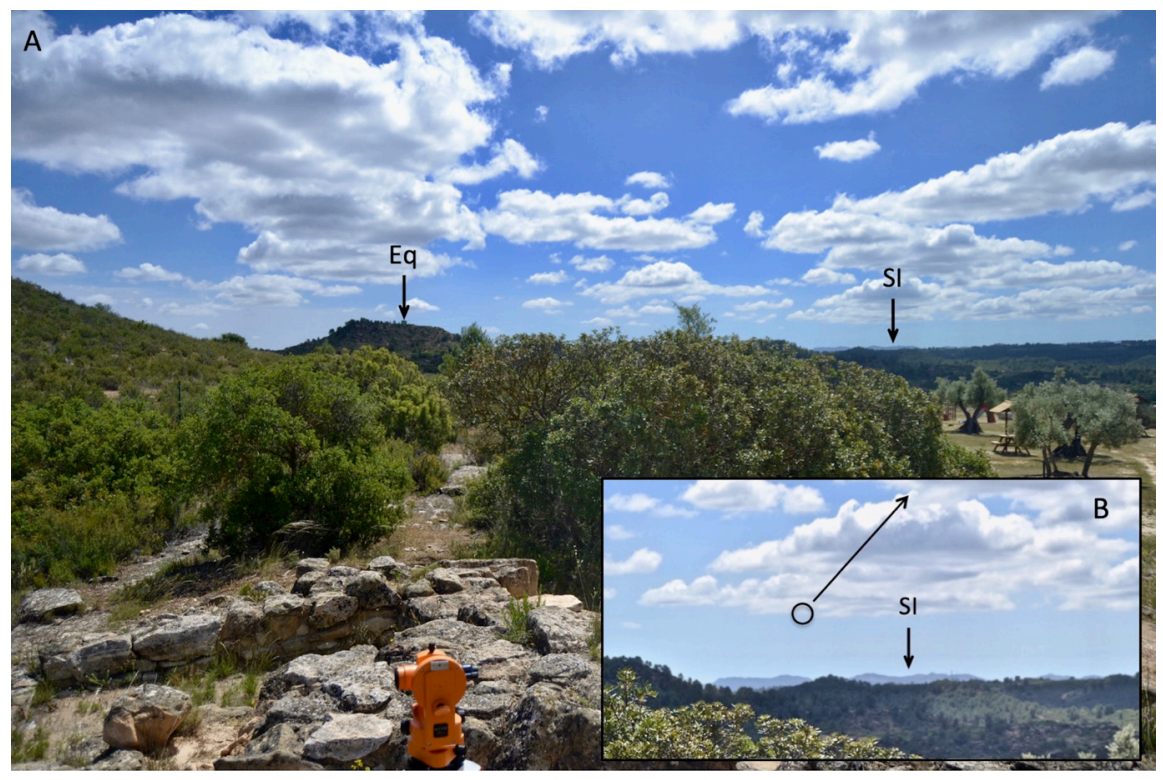

Figura 5: A: Vista parcial del horizonte oriental desde el espacio circular del poblado protohistórico de San Cristóbal de Mazaleón. Se indica la posición de los ortos solares en el equinoccio (Eq) y el solsticio de invierno (SI) en la época de uso del poblado. B: Ampliación de la zona del orto del solsticio de invierno, que se produce sobre las estribaciones meridionales del Montsagre de Paüls. El círculo indica el tamaño angular del disco solar y la flecha oblicua la inclinación de su trayectoria mientras asciende en el cielo.

Aunque desconocemos el desarrollo vertical de las estructuras del poblado de San Cristóbal de Mazaleón, el hecho de que la habitación 2 y el espacio circular adosado se encuentren en su extremo oriental, sugieren la posibilidad -como de hecho se ha constatado en varios yacimientos ibéricos- de que el orto equinoccial que se produce sobre el Tossal de l'Àguila fuese visible a través de alguna abertura o desde la zona de la techumbre o azotea de alguno de los dos espacios.

\subsection{Túmulos de la necrópolis de San Cristóbal}

En el trabajo de campo realizado el 29 de mayo de 2019, también se obtuvieron medidas de la orientación de cinco túmulos que se encuentran distribuidos en dos grupos distantes unos $500 \mathrm{~m}$ al este y ligeramente al sur del poblado $^{10}$ (ver Fig. 1). El primero de ellos, que hemos denominado grupo I, se compone de dos túmulos y el grupo II, localizado a unos $140 \mathrm{~m}$ hacia el este del anterior y en una cota $20 \mathrm{~m}$ superior, de otros tres túmulos ${ }^{11}$. La orientación de las estructuras se midió con la brújula de precisión y se definió como el $A$ definido por el eje del corredor de acceso al túmulo mirando desde el interior de la estructura hacia afuera. En la Tabla 1 mostramos los valores de $A$ (y su $\delta$ asociado) correspondiente a dichas orientaciones. La incertidumbre típica de las medidas de $A$ es de $2^{\circ}\left(1,5^{\circ}\right.$ para $\left.\delta\right)$, lo que tiene en cuenta la escasa precisión que puede alcanzarse considerando la pequeña longitud de las estructuras que definen la orientación (generalmente menor a $1 \mathrm{~m}$ ). Al no disponerse de un clinómetro de mano ni del teodolito a la hora de medir los túmulos, no se pudo medir la altura del horizonte hacia la que apuntaban los monumentos, aunque siempre lo hace hacia lugares lejanos y libres de elementos topográficos relevantes, para los que estimamos una altura aproximada promedio de $1^{\circ}$. Esta última circunstancia también se ha incluido a la hora de estimar la incertidumbre asociada a los valores de $A$.

10 Para la correcta identificación y medición de las cistas, resultó fundamental el trabajo de limpieza realizado por la Comarca del Matarraña, dentro de un conjunto de acciones para musealizar e interpretar diferentes elementos patrimoniales de la zona. Esta limpieza es, asimismo, la que explica que no se hayan realizado mediciones en el resto de túmulos de la necrópolis, debido a su abandono y deterioro, además de la desaparición de alguno de ellos. Recordemos que su excavación se realizó hace más de un siglo.

11 Desgraciadamente, la bibliografía disponible no incluye planos o plantas de la zona de los túmulos o de su estructura individual. 
Tabla 1. Orientaciones de los túmulos medidos de la necrópolis de San Cristóbal.

\begin{tabular}{|c|c|c|c|}
\hline Grupo & Túmulo & $\begin{array}{c}\text { Acimut } \\
\left(\mathbf{(}^{\mathbf{}}\right.\end{array}$ & $\begin{array}{c}\text { Declinación } \\
\left(\mathbf{(}^{\mathbf{}}\right.\end{array}$ \\
\hline I & 1 & $266 \pm 2$ & $-2,4 \pm 1,5$ \\
\hline I & 2 & $240 \pm 2$ & $-21,4 \pm 1,5$ \\
\hline II & 3 & $250 \pm 2$ & $-14,3 \pm 1,5$ \\
\hline II & 4 & $268 \pm 2$ & $-0,9 \pm 1,5$ \\
\hline II & 5 & $267 \pm 2$ & $-1,6 \pm 1,5$ \\
\hline
\end{tabular}

En la Fig. 6 mostramos el diagrama de orientaciones de los corredores de acceso a los túmulos medidos de la necrópolis de San Cristóbal. Como podemos ver, todos ellos se encuentran orientados hacia poniente, precisamente hacia una zona relativamente estrecha del horizonte definida por el rango de los ortos solares durante el otoño e invierno, entre ambos equinoccios y el solsticio de invierno. Es importante hacer notar que, debido a la localización de los túmulos sobre una ligera pendiente del terreno que desciende hacia el oeste, todos ellos tienen una visión libre de la mitad poniente del horizonte, lo que recalca la im- portancia de esta zona en la localización y disposición de los monumentos, sugiriendo que hubo una cierta voluntad a que los monumentos "mirasen" hacia el oeste. En el caso de los túmulos del grupo I, la otra mitad del horizonte, la oriental, está a corta distancia y no contiene ningún elemento topográfico destacable, por lo que carece de interés. En el caso del grupo II tenemos una situación similar aunque, en este caso, al estar situados en una cota algo superior, el horizonte oriental se encuentra más lejano, siendo el Tossal de l'Àguila, a una distancia de unos $450 \mathrm{~m}$, el único elemento topográfico destacable en esa dirección.

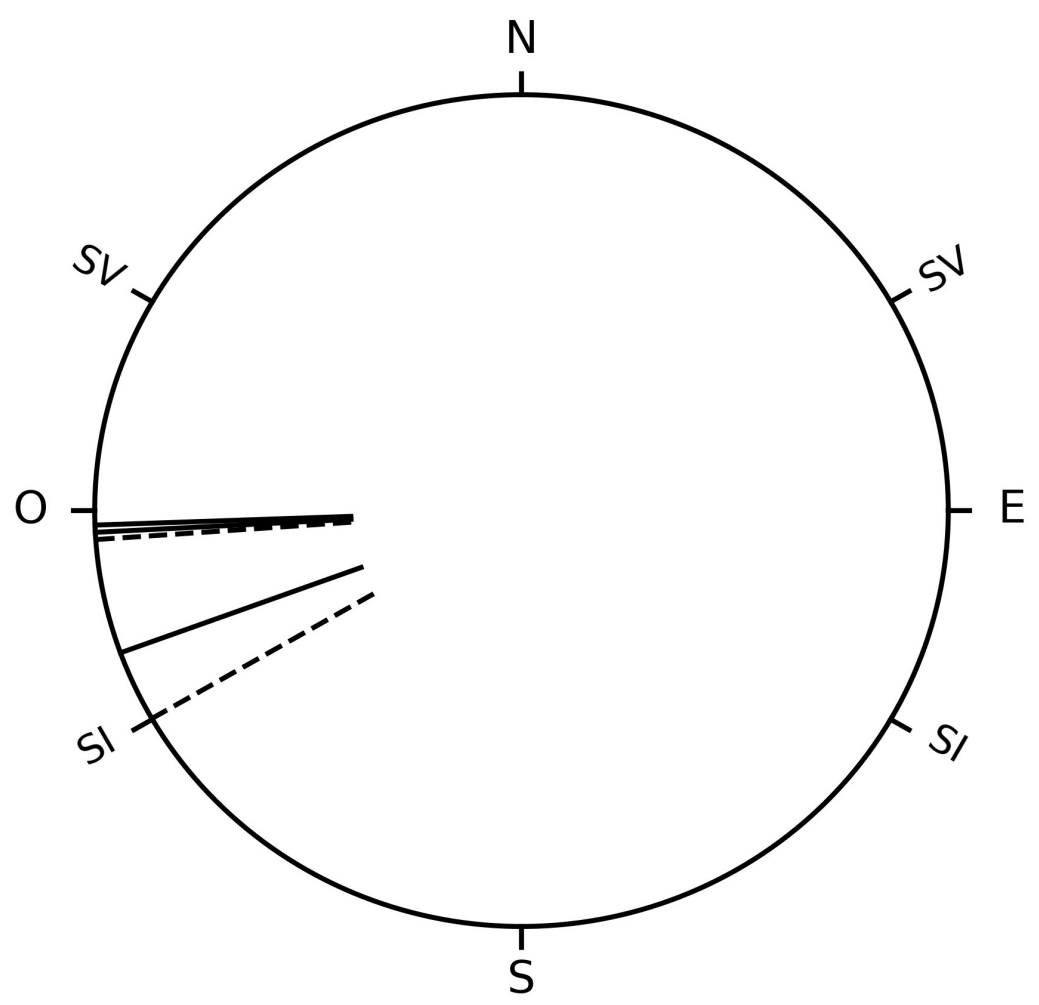

Figura 6: Diagrama de orientaciones de los accesos de los túmulos medidos de la necrópolis asociada el poblado protohistórico de San Cristóbal de Mazaleón. Las líneas discontinuas representan los túmulos del grupo I y los de líneas continuas los del grupo II. En la figura se indican los puntos cardinales así como los ortos y ocasos solares en el solsticio de verano (SV) y el solsticio de invierno (SI) 
Aunque todavía no existe ningún estudio sistemático sobre las orientaciones de los túmulos protohistóricos del Bajo Aragón, una revisión de los planos y croquis de los diarios de excavación publicados por Rafel (2003) indica claramente que todos los túmulos recogidos en dicho trabajo están orientados hacia poniente, un $42 \%$ de ellos hacia el suroeste, un $32 \%$ hacia el noroeste y un $26 \%$ hacia el punto cardinal oeste. Hay que tener en cuenta que las orientaciones que obtenemos de dicha publicación se basan en ángulos horizontales respecto al norte magnético ( $\sin$ corregir de declinación magnética) por lo que son solo aproximadas. De cualquier manera, resulta claro que el patrón de orientación que encontramos en los túmulos de San Cristóbal de Mazaleón es coincidente con el que presenta la mayor parte del resto de los túmulos protohistóricos del Bajo Aragón. Esta cuestión se discutirá más ampliamente en la sección 4.2.

Volviendo a los datos recogidos en la Tabla 1 y la Fig. 6, resulta interesante que tres de los túmulos muestran orientaciones consistentes, dentro de las incertidumbres y considerando la altura del horizonte $\left(\approx 1^{\circ}\right)$, con el ocaso solar en los equinoccios. El túmulo 2 del grupo I muestra una orientación cercana al ocaso del sol en el solsticio de invierno, mientras que el mayor de todos, el número 3 del grupo II, muestra una orientación intermedia, hacia el ocaso en una fecha sin un interés objetivo especial. Sin embargo, es posible que su orientación pueda explicarse por su situación con respecto al Tossal de l'Àguila, que, como mostramos en la Figura 6, se encuentra alineado, hacia el este, con el eje del corredor del túmulo. Hay que tener en cuenta que, desde el emplazamiento del túmulo, la posición del cerro ya no coincide con el orto solar en los equinoccios. Estimamos que el amanecer se produciría sobre el cerro y alineado con el corredor del túmulo entre 30 y 40 días antes y entre 30 y 40 después del solsticio de verano, unas fechas sin interés astronómico particular. En la Fig. 7 podemos ver que, hacia el este, los corredores de los otros dos túmulos del grupo II apuntan hacia el extremos sur del Tossal de l’Águila. Hay que recordar que esta elevación no resulta visible desde los túmulos del grupo I.

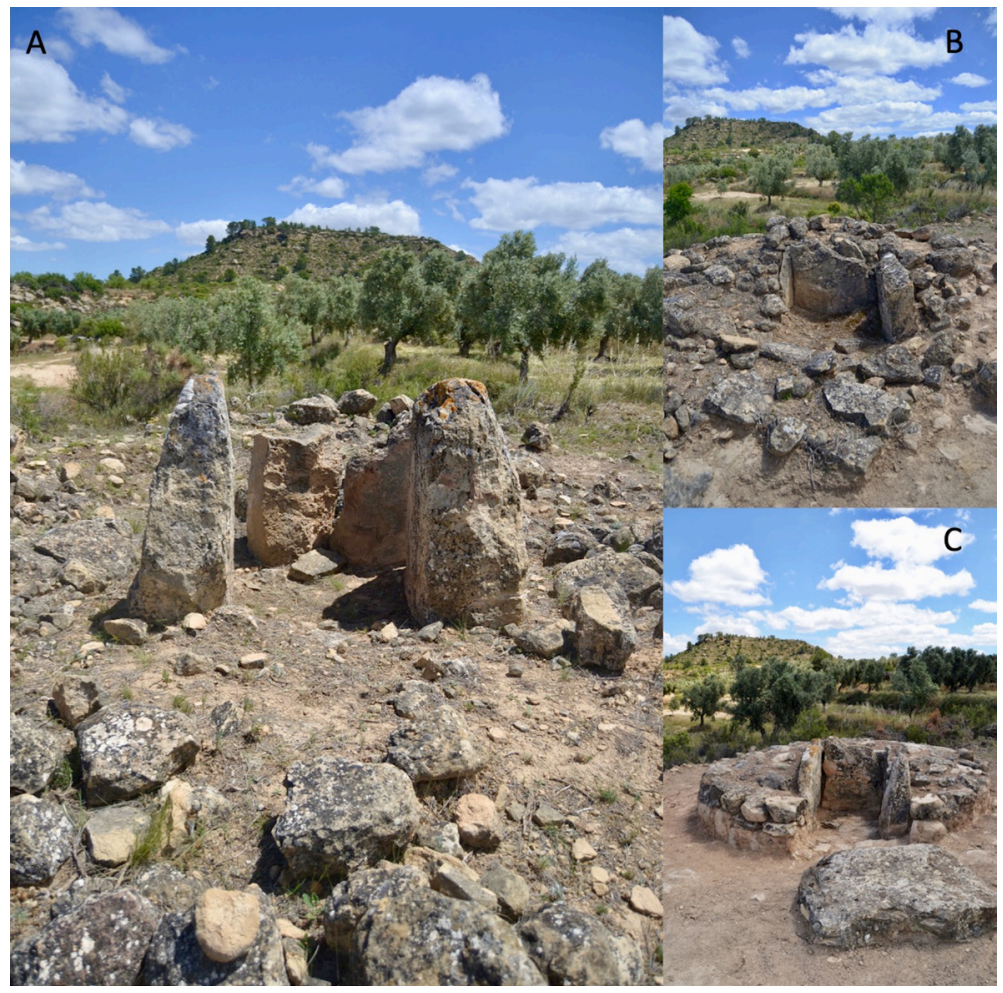

Figura 7: Vistas parciales del horizonte oriental desde los tres túmulos del grupo II de la necrópolis asociada el poblado protohistórico de San Cristóbal de Mazaleón. A: Vista desde el túmulo 3, el de mayor tamaño, situado al sur del grupo. Podemos ver que, hacia el este, está alineado con la parte central del Tossal de l'Àguila. El resto de túmulos del grupo II, números 4 (B) y 5 (C) apuntan hacia la ladera sur del Tossal de l'Àguila. 


\section{Discusión}

\subsection{La orientación de la habitación 2 y el marcador equinoccial}

Una fracción importante de los lugares de culto ibéricos presentan marcadores del orto equinoccial o del PMTS ${ }^{12}$ sobre elementos topográficos prominentes del horizonte oriental. Esteban (2016, 2017: 91-103) presenta y discute las características de dichos marcadores, concluyendo que el orto del equinoccio o del PMTS podría haber sido utilizado para la elaboración del calendario y como un elemento en los rituales celebrados en el santuario. Un ritual que, al menos en algunos yacimientos, pudo haber tenido una dimensión pública.

En varios de los lugares de culto que presentan marcadores equinocciales, sus edificios principales se encuentran orientados a lo largo de los ejes cardinales, de forma que los muros este-oeste apuntan hacia el marcador, lo que hace más verosímil la existencia de una motivación astronómica tanto en la elección de su emplazamiento como en la disposición espacial de los ejes de simetría de la estructura del santuario. Los yacimientos ibéricos de este tipo que conocemos hasta la fecha son el Tossal de Sant Miquel (Llíria, Valencia; Esteban y Moret 2006), La Malladeta (La Vila Joiosa, Alicante; Esteban y Espinosa Ruiz 2018), Cerro de las Cabezas (Valdepeñas, Ciudad Real; Esteban y Benítez de Lugo Enrich 2016) y el Santuario de la Puerta del Sol en Puente Tablas (Ruiz Rodríguez et al. 2015). El santuario de La Malladeta es un complejo cultual aislado situado sobre la cumbre de un promontorio costero y separado unos $1,5 \mathrm{~km}$ de la ciudad ibérica de Álon. Este yacimiento consta de varios edificios dispuestos sobre la cumbre y la ladera sur del promontorio, todos ellos relacionados con las actividades del santuario (Rouillard et al. 2014). Los santuarios del Tossal de Sant Miquel, Cerro de las Cabezas o el Santuario de la Puerta del Sol son, como la habitación 2 de San Cristóbal de Mazaleón, estancias o un conjunto de ellas integradas dentro de la trama urbana de un poblado.

Bonet y Mata (1997) identificaron el denominado departamento 14 del poblado edetano del Tossal de Sant Miquel como el núcleo de un complejo de construcciones de carácter sacro de unos $70 \mathrm{~m}^{2}$. Este edificio está situado en una zona elevada del poblado, construido sobre una pequeña montaña y cuyo trazado viene determinado por las terrazas artificiales con las que se acondicionó la pendiente de las laderas sobre las que se levantan los edificios. La orientación las distintas estructuras es variable según la disposición de las terrazas, pero los departamentos 12, 13 y 14, que conforman el complejo cultual, se encuentran orientados exactamente en la dirección este-oeste, una disposición que no comparten los edificios de sus alrededores. La entrada al santuario se produce por su fachada oriental, que se encuentra, y esto nos parece muy significativo, frente a un área o plaza relativamente amplia libre de edificaciones (ver figura 9 de Bonet y Mata 2009). Este hecho, junto a que la pendiente del terreno cae de forma acentuada en dirección este-sureste, permitirían la visión libre del horizonte oriental desde la entrada del santuario. Esteban y Moret (2006) creen que esta disposición pudo ser intencionada con el fin de observar el orto solar sobre la cumbre de un pequeño cerro distante, el Cabeç Bord, que podría haber sido utilizado como marcador del equinoccio. Como vemos, en el Tossal de Sant Miquel tenemos un ejemplo donde los requerimientos de una orientación y observación astronómicas (en este caso equinoccial) pudieron determinar la disposición de una parte de la trama urbana de un poblado ibérico.

Otro tipo de orientación equinoccial es el que muestra el santuario denominado de la Puerta del Sol en el oppidum oretano de Puente Tablas (Jaén, Ruiz et al., 2015, Pérez Gutiérrez et al. 2016), un gran complejo cultual de 300 $\mathrm{m}^{2}$ de extensión que se encuentra situado junto a una puerta de la muralla perimetral orientada hacia el este. En este santuario no tenemos un marcador sobre un elemento del horizonte, sino que el equinoccio se manifestaba en forma de un curioso fenómeno de iluminación durante y tras el orto solar sobre una estela, que representa de forma esquemática una divinidad femenina y que se encontraba situada en el eje de la vía de acceso que parte de la citada puerta. Otro posible efecto de iluminación (aunque

12 De aquí en adelante, cuando hagamos referencia a un marcador $\mathrm{u}$ orientación equinoccial consideraremos de forma implícita que puede relacionarse tanto con el orto u ocaso del equinoccio como con el del PMTS, sin distinguir si el objetivo del marcador u orientación es un evento u otro. Esto se debe a que la posición del Sol en ambos casos es muy similar y, en la mayoría de los casos, la precisión de las medidas no permite distinguir entre ambos. 
más inseguro debido a que está basado en la reconstrucción de la estructura vertical que se le supone al complejo) se podría haber producido en las pequeñas cuevas que se encuentran en el lado occidental del complejo. Ruiz et al. (2015) consideran que ambos, la Puerta del Sol de la muralla y el santuario asociado, se construyeron a la vez en la segunda mitad del siglo $\mathrm{V}$ a. C. y con una motivación astronómica.

En el oppidum de Cerro de las Cabezas encontramos el denominado "santuario de entrada" (Moneo et al. 2001), una estancia con una singular estructura pentagonal que muestra dos de los muros orientados hacia sendos ortos solares, uno hacia el equinoccio y otro hacia el solsticio de verano (Esteban y Benítez de Lugo Enrich 2016). Como en otros marcadores ibéricos, el orto solar equinoccial se produce sobre la cumbre de un cerro lejano que podría haber sido utilizado como marcador. En este santuario, aunque desconocemos cuál fue su estructura vertical, es probable que la visión del horizonte se encontrara obstaculizado por la muralla del poblado, por lo que las orientaciones podrían haber tenido un sentido simbólico y no práctico, es decir, podrían haber sido orientadas de manera ritual y que no se utilizaran para observación astronómica.

La cronología de los santuarios que muestran marcadores o relaciones equinocciales citados anteriormente es un dato de especial interés. El santuario de Cerro de las Cabezas se ha fechado en el siglo III a.C. (Moneo et al. 2001), presentando la cronología más tardía del grupo. La ocupación del poblado de Sant Miquel de Llíria se establece entre los siglos V y II a.C. (Bonet 1995), aunque se desconoce cuando se construyó el edificio 14, las evidencias muestran que dejó de utilizarse en el siglo II a.C. Por otra parte, el santuario costero de La Malladeta comenzó su funcionamiento en el siglo IV a.C. (Rouillard et al. 2014). El santuario de la Puerta del Sol de Puente Tablas parece ser el más temprano del grupo, con una cronología que alcanza el siglo V a.C. (Ruiz et al. 2015). En base a estos datos y las cronologías de otros yacimientos con similitudes, Esteban (2017: 98) propuso el siglo V a.C. como la época post quem a partir de la cual aparecieron los ritos relacionados con el equinoccio entre los iberos. Sin embargo, esta propuesta parece refutada con la cronología del poblado de San Cristóbal de Mazaleón, que se encuadra entre la segunda mitad del siglo VII y la primera mitad del siglo VI a. C. (Fatás 2007;
Sanmartí-Grego 1979: 145), dentro de un contexto preibérico, lo que indica que el origen de la importancia del equinoccio en la orientación de edificios de culto ibéricos y el uso de marcadores de este evento astronómico podría haber tenido un origen anterior al siglo $\mathrm{V}$ a.C., aunque, a la luz de las evidencias recogidas hasta la fecha, su uso se haría más frecuente en épocas ibéricas plena y tardía, a partir del siglo IV a.C.

Como ya se comentó en la sección 3.1 , la orientación de la habitación 2 se ajusta perfectamente a los ejes cardinales y, por otra parte, esta disposición parecería estar relacionada de forma práctica como observatorio del marcador del orto solar equinoccial sobre el Tossal de l'Àguila. Estas características hacen de la habitación 2 un análogo a los santuarios ibéricos equinocciales citados anteriormente y parecen apoyar el carácter cultual o ceremonial de este espacio singular. Como discute Fatás (2004-2005) y hemos referido anteriormente, aunque esta habitación no presenta ninguna diferenciación arquitectónica respecto a las otras del poblado, son varios los materiales hallados en las excavaciones que indican su carácter singular y que también son consistentes con un uso cultual o ritual. Por una parte, es la única estancia del poblado que presenta un revestimiento decorado en sus paredes y pudo contener también un pilar revestido de barro, un elemento frecuente en lugares sacros en el ámbito ibérico. La presencia de productos importados como fragmentos cerámicos policromados de un vaso fenicio occidental tipo "Cruz del Negro" indican también un ámbito de prestigio. Finalmente, el hallazgo de objetos de barro con molduras triangulares decoradas, así como de pies o soportes de barro, sugieren la posible presencia de hogares fijos decorados así como de mesas o altares de ofrendas portátiles (Fatás 2004-2005), elementos rituales frecuentes en ámbitos de carácter cultual en todo el ámbito ibérico septentrional que indicarían, en opinión de Almagro-Gorbea y Moneo (2000), la fuerte componente indoeuropea presente en dicha zona relacionada con la tradición de los Campos de Urnas.

Como vemos, la orientación de la habitación 2 a lo largo de los puntos cardinales junto a las características del material arqueológico encontrado en su interior son coherentes con un uso cultual. Podríamos estar pues ante un santuario integrado en un entorno doméstico alrededor de un hogar, dirigido posiblemente 
por unas élites guerreras de substrato indoeuropeo o ante espacios domésticos en los que se practicarían actividades "conviviales", tal y como Vives Ferrándiz (2005) ha propuesto para ámbitos más meridionales -pero con similares cronologías- o Sardà (2010) para zonas más próximas. De hecho parecería que la orientación astronómica y/o respecto a los ejes cardinales debió constituir un elemento esencial y duradero en el ritual ibérico. Según Almagro Gorbea (1993-1994) o Moneo (2003: 463), en las últimas fases de la Cultura Ibérica, los santuarios gentilicios de tipo familiar de la zona septentrional peninsular, se transformaron en santuarios de carácter público, situados en edificios aislados, generalmente en la zona más alta de los poblados que, en los casos más evolucionados, podrían interpretarse como templa definidos, según Moneo (2003: 463), como "edificios construidos ex-profeso con rituales de fundación que incluían una orientación astronómica basada en concepciones cósmicas seguramente de tipo augural". El ejemplo de la habitación 2 de San Cristóbal de Mazaleón parece indicar que estas características astronómicas de orientación de los templa también fueron aplicadas en santuarios domésticos (o espacios de carácter mixto doméstico-ceremonial) desde una época temprana preibérica, tal como indica la cronología del yacimiento.

La orientación astronómica de la habitación 2 , debido a su integración como un espacio más del poblado fue posiblemente el motivo que determinó el trazado urbano (al menos de parte de él), lo que quizás se realizaría mediante un cierto rito fundacional o augural en el que la deposición de los huesos de suido y cánido también pudieron estar implicados. La observación del orto equinoccial precisamente sobre el Tossal de l'Àguila no solo determinaría la orientación de la habitación 2 , sino también la localización exacta de este espacio ritual, tanto geográfica como con respecto al poblado, pues necesariamente debió colocarse en el extremo oriental para asegurar la observación del orto solar vinculado, además, al levantamiento del elemento turriforme que quizás se utilizó para dicha actividad astronómica. Como ya comentamos anteriormente, las restricciones geográficas impuestas por la observación de un evento solar sobre un marcador topográfico también serían determinantes en la localización exacta de otros santuarios ibéricos (ver Esteban 2017). Es importante remarcar que la perspectiva arqueoastronómica aporta nuevos elementos a considerar para entender la localización y disposición espacial de los recintos de culto ibéricos y, quizás también de los núcleos de habitación asociados a ellos, como es el caso de San Cristóbal de Mazaleón. La mayoría de emplazamientos de culto y habitacionales ibéricos se sitúan en lugares elevados, algo que tradicionalmente se ha entendido como una necesidad del control territorial y de las comunicaciones que, en el caso de las poblaciones, tendría un claro objetivo defensivo. Los hallazgos arqueoastronómicos de las últimas décadas abren la posibilidad de que, en algunos de estos yacimientos, la selección de su emplazamiento fuese determinado por la observación de ortos u ocasos solares (o de otros astros) en condiciones especiales y fechas singulares, lo que explicaría su relación frecuente con lugares altos (actuando en alguna forma como "observatorios"). Por otra parte, los lugares altos también tienen una connotación simbólica adicional, pues pueden ser percibidos como más cercanos a la divinidad, más aún cuando esta divinidad (o divinidades) tienen atributos celestes asociados, como parecen sugerir los hallazgos arqueoastronómicos.

Una cuestión pertinente por resolver es por qué se utilizó precisamente el Tossal de l'Àguila como marcador equinoccial. En otros yacimientos donde tenemos marcadores de este tipo carecemos de referencias sobre la importancia arqueológica del elemento topográfico sobre el que se produce el orto u ocaso, por lo que su interés parece solo circunstancial como elemento necesario del marcador. En el caso del Tossal de l'Àguila, la situación no es muy diferente. La única referencia arqueológica relacionada con él es la recogida por Vallespí (2001), citando los trabajos del cura rural Evaristo Colera Soldevilla, precursor del reconocimiento arqueológico del Bajo Aragón, que en sus notas manuscritas recogidas entre 1804 y 1832, indica el hallazgo de sepulturas con ajuares en el Tossal de l'Àguila, aunque desconocemos cualquier dato acerca de su número, tipología y localización exacta, esta breve noticia deja abierta la cuestión.

Un último aspecto a abordar es el de la importancia del equinoccio o el PMTS en el posible ritual celebrado en la habitación 2 del poblado de San Cristóbal de Mazaleón. Parece claro que estaríamos frente a una celebración que se llevaría a cabo a comienzos de la primavera, el otoño o en ambos momentos del año, por lo que estaría directamente relacionada 
con la estacionalidad y los ciclos de la naturaleza. El uso de una fecha como los equinoccios o el PMTS, que divide en dos partes de igual duración el tiempo que transcurre entre ambos solsticios, indica que el calendario (pre)ibérico debió tener una estructura básica de, al menos, dos periodos de unos seis meses, de una manera similar a las dos "macro-estaciones" célticas (Duval y Pinault 1986: 404-405), aunque es más que probable que tuviera una estructura cuatripartita y que los solsticios también tuvieran un carácter calendárico-ritual (como sugieren los resultados para distintos yacimientos, ver Esteban 2017: 102-103). Una estructura de dos grandes periodos de seis meses también ha sido propuesta por Moneo (2003: 368) o por Chapa y Mayoral (2007: 27-33) y, según indica Moneo (2003: 368), también se documenta en otras partes del Mediterráneo Oriental, como el Próximo Oriente o Mesopotamia. Durante el periodo de primavera-verano el día tiene una mayor duración que la noche y el Sol adquiere posiciones máximas más altas sobre el horizonte (pudiendo denominarlo "periodo de luz"), mientras que en el de otoño-invierno la noche dura más que el día y la altura máxima que alcanza el sol es menor ("periodo de oscuridad"). Ambos equinoccios o PMTS corresponderían a los momentos en que comienzan y acaban estos dos periodos y están, además, relacionados con momentos clave del ciclo agrario-pastoril. En el Mediterráneo antiguo e incluso en la propia Gades, el inicio del año agrícola y de la estación de la cosecha se celebraba con la muerte y resurrección o egersis de Melkart que, según algunos autores, podrían haber tenido lugar en la luna nueva más cercana al equinoccio de primavera (Cohen 1993: 401). En la egersis se celebraba la hierogamia o matrimonio sagrado de dicho dios con Astarté, con el fin de asegurar la renovación del ciclo natural de los vegetales, animales y seres humanos (ver Moneo 2003: 369). Una narración mítica de este tipo, donde el protagonista sería un posible dios-héroe de la vegetación, podría corresponder a la representada en los relieves del monumento funerario de Pozo Moro (Moneo 2003: 416). El equinoccio de otoño marcaba el inicio de la estación de la siembra (Chapa y Mayoral 2007: 27-32). Una de las celebraciones más famosas de la antigüedad relacionadas con este momento de año son las dedicadas a la diosa griega Deméter, cuyos Grandes Misterios se representaban en Eleusis a comienzos del otoño (Espejo Muriel
1995: 95) o en la festividad de las Temosforias de Atenas (ver Moneo 2003: 369). Los Misterios de Eleusis representaban el ciclo vegetativo anual mediante el mito del descenso y salida de Koré del inframundo, una simbología cíclica con una clara inspiración en el movimiento anual solar sobre la esfera celeste (ver Esteban 2013: 480-481, 2017: 99). En el santuario ibérico de la cueva de La Lobera tenemos un efecto de iluminación que se produce exactamente durante el ocaso solar de los PMTS que podría representar de manera simbólica el ascenso y descenso periódicos al inframundo de una diosa ibérica de la fertilidad (Esteban et al. 2014).

En la habitación 2 del poblado de San Cristóbal de Mazaleón tendríamos un ritual de carácter "convivial" asociado al ciclo vegetativo y la fecundidad que se celebraría en uno o en los dos equinoccios. El ámbito de estas celebraciones debió ser necesariamente restringido o familiar debido al tamaño de la estancia. Una posible vía de interpretación implicaría al jefe de la comunidad (o alguien en la comunidad con un cierto prestigio/jerarquía) obrando como sacerdote o como representante o personificación de la divinidad, quien buscaría mantener y potenciar "la fertilidad de la tierra, la producción de las cosechas y la conservación de las reservas de alimento de toda la comunidad" (Almagro Gorbea 1993-94). El oficiante, indudablemente con ciertos conocimientos astronómicos, actuaría de un modo que quizás pudiera recordar a los augures de la religión etrusca o romana. Hay que recordar que el propio dios Melkart era la divinidad poliada de la ciudad fenicia de Tiro que ostentaba el título de señor de la ciudad y fundador de la dinastía reinante (Almagro Gorbea 1993-94) y que, en cierta manera, podrían aplicarse a la relación entre las jerarquías ibéricas con las divinidades protectoras. No obstante, tampoco se puede descartar que se tratasen de ceremonias de convivialidad con una menor presencia de lo sagrado y en las que se renegociasen las identidades en las relaciones sociales mediante un consumo ritual de ciertos productos, aunque, a juzgar por los interesantes resultados que presentamos, la astronomía tendría en esta otra hipótesis un papel simbólico igualmente relevante.

El único trabajo arqueoastronómico de un yacimiento cercano y que podríamos considerar contemporáneo al que nos ocupa es el del edificio singular del Turó del Calvari en Vilalba dels Arcs (Tarragona), situado a unos 
$25 \mathrm{~km}$ del poblado de San Cristóbal de Mazaleón (Pérez Gutiérrez et al. 2011, 2016) y con el que presenta ciertos paralelos en su interpretación arqueológica, con todas las salvedades del conjunto de su cultura material y características constructivas. Se trata de un edificio aislado de dimensiones importantes situado en una pequeña elevación, muy alejado de cualquier poblado de la época y que se construyó en la primera mitad del siglo VI a.C. (Bea y Diloli 2005). El material encontrado en su interior indica una finalidad ritual, como vasijas para ofrendas, mesas de altar, vajillas de tipo fenicio o ánforas para vino, elementos que ilustran la existencia de una diferenciación social (Bea y Diloli 2005). El edificio ha sido interpretado como un centro ceremonial para el territorio colindante, articulado a través de ceremonias y banquetes, utilizado por las elites como un mecanismo de poder a través de una cierta ritualidad del consumo de bienes de prestigio (Diloli, Bea y Sardà 2018). La entrada del edificio se realiza por el noroeste, algo poco común en los edificios de culto aislados ibéricos. El eje mayor del recinto, en el sentido hacia donde apunta el acceso, mira hacia un área del horizonte que carece de marcadores topográficos y demasiado al norte como para relacionarlo con ocasos solares o lunares. Pérez Gutiérrez et al. $(2011,2016)$ proponen que dicho eje apunta hacia el ocaso de la estrella Arturo en la época de la construcción del yacimiento, la tercera estrella más brillante en el cielo del siglo VI a.C. Según dichos autores, el patrón de la proyección de la luz del ocaso solar que atraviesa la entrada sobre la pared norte podría indicar los equinoccios y el solsticio de verano, aunque esta hipótesis se basa en alineaciones secundarias, por lo que su grado de verosimilitud puede ser discutible. Como vemos, el edificio de Turó del Calvari, aunque con un claro carácter cultual y posibles relaciones astrales, muestra unas características constructivas y arqueoastronómicas diferentes a las del recinto que estudiamos en el presente trabajo y diferentes también a las de la mayoría de lugares de culto ibéricos.

\subsection{La orientación de los túmulos de la necrópolis de San Cristóbal}

Como ya comentamos en la sección 3.2, los datos mostrados tanto en la Tabla 1 como la Figura 5 indican que los cinco túmulos estudiados poseen una orientación hacia el oeste-suroeste ocupando un rango de $A$ bastante restringido, una característica que parece común en el resto de túmulos protohistóricos del Bajo Aragón, por lo menos en la muestra de monumentos de este tipo publicados por Rafel (2003).

Disponemos de muy escasos estudios arqueoastronómicos sobre orientaciones de tumbas en el mundo ibérico y todavía ninguno de carácter sistemático. Algo más conocemos de etapas anteriores de la protohistoria. Las tumbas del periodo fenicio arcaico del sur de la península ibérica tienden a disponer sus ejes longitudinales cerca de la línea este-oeste (Ramos Sainz 1986: 32) y con sus entradas orientadas hacia el este que, en algunos casos, podrían relacionarse con el orto solar en el solsticio de invierno y los equinoccios (Belmonte 1999: 186). Esteban (2014) estudió la necrópolis orientalizante de La Angorrilla (Alcalá del Río, Sevilla, siglos VII a VI a.C.), cuyas sepulturas, clasificadas mayoritariamente como fosas rectangulares de tendencia trapezoidal (Fernández Flores et al. 2014), muestran una distribución de orientación de sus ejes mayores similar a la de otras necrópolis fenicias arcaicas e incluso posteriores de época púnica del Mediterráneo occidental (ver discusión en Esteban 2017: 83-84). Aunque se dispone de la orientación del eje longitudinal de las sepulturas, no sabemos con certeza cuál era la dirección relevante, si el este o el oeste, aunque las cabezas de los cadáveres inhumados se sitúan en el extremo poniente de la sepultura. Hacia el oeste, la distribución de la orientación de las fosas de La Angorrilla resulta similar a la de los túmulos de San Cristóbal, con la mayor concentración entre el ocaso equinoccial y el del solsticio de invierno. Por otra parte, la necrópolis de Cerrillo Blanco (Porcuna, Jaén), también con una cronología del siglo VII a.C. (Fernández y Rodríguez 2007), reproduce un patrón de orientación semejante al de La Angorrilla (Esteban 2014).

Los estudios arqueológicos que recogen la orientación de las tumbas en las necrópolis ibéricas del sureste indican que suelen disponerse a lo largo de unos ejes de simetría (García-Gelabert 1999). En Los Villares, Los Nietos, Cabezo Lucero o La Albufereta las tumbas tumulares se encuentran orientadas siguiendo los ejes cardinales (Blánquez 1990: 123, García Cano 1990, Aranegui et al. 1985, Rubio 1986: 382). Esta regularidad en el trazado y ordenación de las necrópolis también se observa en yacimientos del noreste de Andalucía 
como en Estacar de Robarinas (García-Gelabert y Blázquez 1992) y en Castellones de Céal (Chapa y Pereira 1992). Por otro lado, según indican Aranegui et al. (1983), es frecuente que las falcatas se encuentren depositadas a lo largo de la dirección este-oeste dentro de los enterramientos ibéricos.

La existencia de un posible patrón de orientación a lo largo del eje este-oeste en las tumbas de las necrópolis ibéricas parece similar al que muestran los edificios de culto de esta cultura protohistórica (ver Esteban 2017: 92-93), hecho que sugiere que ambas características podrían obedecer a un mismo principio dentro de la cosmovision ibérica, apoyando la relación íntima entre sus mundos religioso y funerario. Como ya se indicó anteriormente, no hay estudios arqueoastronómicos sistemáticos de necrópolis ibéricas, algo que está todavía por realizar, sin embargo hay algunos resultados puntuales que refuerzan estos elementos comunes con los santuarios. Rodríguez-Ariza y Pérez Gutiérrez (2013) estudiaron la orientación del túmulo 20 de la necrópolis ibérica de Tútugi (Galera, Granada), construido en el siglo $\mathrm{V}$ a. C. y que contiene una cámara subterránea rectangular a la que se accede por un corredor abierto a poniente. Dicho corredor se encuentra orientado hacia el ocaso solar en las cercanías del equinoccio, que podría iluminar durante breves momentos el interior de la cámara. En la necrópolis de Cabezo Lucero (Guardamar del Segura, Alicante), datada entre el siglo $\mathrm{V}$ al IV a.C., tenemos un posible ejemplo de marcador del ocaso equinoccial sobre el cercano cerro del Cabezo Soler (Esteban 2002), un marcador muy similar al que encontramos en el poblado de San Cristóbal de Mazaleón aunque, en el caso de la necrópolis alicantina, el marcador se sitúa a poniente. Como ya se dijo, los túmulos de Cabezo Lucero se encuentran orientados en la dirección este-oeste, por lo que se alinean simultáneamente con el Cabezo Soler y hacia el ocaso equinoccial. Quizás, el yacimiento que mejor pueda ilustrar la relación entre el mundo religioso y funerario ibérico sea el monumento turriforme de El Pajarillo (Huelma, Jaén), de corta existencia y fechado entre finales del siglo $\mathrm{V}$ y principios del IV a. C. Este edificio estaba asociado a una pequeña necrópolis y contenía un conjunto escultórico que narra el combate mítico de un hombre armado contra bestias (Molinos et al. 1998). El yacimiento se ha interpretado como un santuario dedicado a un héroe de la comu- nidad, se trataría de un heroon. El eje mayor de la estructura se disponía aproximadamente a lo largo del eje norte sur y las piezas escultóricas estarían mirando hacia el oeste, pues es en esta dirección donde se encuentra el cruce de caminos que controla uno de los pasos entre el Alto Guadalquivir y la depresión de Guadix y donde vierte la ladera del pequeño cerro donde se ubica el monumento. En un estudio arqueoastronómico preliminar del lugar encontramos dos posibles marcadores astronómicos sobre el horizonte poniente, uno que indicaría el ocaso solar en el PMTS y otro el solsticio de invierno (ver figura 6 de Esteban 2017). Como vemos, las relaciones astronómicas en santuarios y monumentos funerarios ibéricos muestran claros paralelismos, donde la disposición espacial y su alineamiento respecto a ejes con significado solar (equinoccios principalmente, aunque también solsticios) son elementos determinantes. La principal diferencia entre ambos tipos de construcciones es si la relación astronómica se produce con los ortos u ocasos. Mientras los santuarios muestran relación mayoritaria hacia los ortos, los elementos funerarios muestran una predilección hacia los ocasos, una característica que también comparten las cuevas-santuario ibéricas (ver Esteban 2017: 103-105), quizás por la relación de ambos tipos de ámbitos con el inframundo. Esta sistemática nos sugiere que mientras en los santuarios tendríamos un culto con carácter cósmico, los monumentos funerarios y las cuevas estarían relacionadas con los aspectos ctónicos de las divinidades y la religión ibéricas.

\section{Conclusiones}

El estudio arqueoastronómico llevado a cabo muestra que la denominada habitación 2 del poblado de San Cristóbal de Mazaleón presenta características similares a varios santuarios ibéricos del sureste; una estructura ortogonal con una orientación muy ajustada a los ejes cardinales y la presencia de un marcador del orto solar en fechas alrededor de los equinoccios sobre la parte central del cerro que domina el horizonte oriental del yacimiento, el Tossal de l'Àguila. Estas características junto con las evidencias arqueológicas que lo denotan como un edificio singular nos llevan a proponer su uso bien como espacio sacro, donde se llevarían a cabo ritos propiciatorios de la fertilidad en los equinoccios o en el punto medio tem- 
poral entre solsticios (PMTS), que serían hitos del calendario agrario-pastoril de la comunidad, o bien como escenario de ceremonias redistributivas, en las que se renegociarían las identidades en las relaciones sociales a través de un consumo ritual de ciertos bienes, pero que estarían igualmente pautadas por los momentos antes señalados: equinoccios o PMTS. La comparación de las cronologías de otros santuarios protohistóricos con marcadores equinocciales indican que el edificio de culto de San Cristóbal, construido entre la segunda mitad del siglo VII y la primera mitad del siglo VI a.C. es, por ahora, el más temprano de todos ellos.

Los cinco túmulos de la necrópolis del poblado de San Cristóbal que estudiamos en este trabajo muestran un patrón de orientaciones bien definido hacia el oeste-suroeste, similar al que muestra la mayoría de los túmulos protohistóricos de otras necrópolis del Bajo Aragón. Estos alineamientos podrían estar relacionados con el ocaso solar, mayoritariamente cercano a los equinoccios y con unas implicaciones simbólicas bien distintas a las referidas en el espacio de hábitat. De esta manera, tanto la ciudad de los vivos, como la ciudad de los muertos, al menos en la parte que hemos podido analizar, estarían dispuestas obedeciendo ciertas concepciones rituales e ideológicas claramente relacionadas con referentes físicos celestes y que obedecerían a preceptos de una cosmovisión ibérica todavía por desvelar.

\section{Bibliografía}

Almagro Gorbea, M. (1993-1994): Ritos y cultos funerarios en el mundo ibérico. Anales de prehistoria y arqueología, 9-10: 107-133.

Almagro Gorbea, M.; Moneo, T. (2000): Santuarios urbanos en el mundo ibérico. Real Academia de la Historia, Madrid.

Aranegui, C.; Jodin, A.; Llobregat, E. A.; Rouillard, P.; Uroz, J. (1985): Fouilles du site ibérique de Cabezo Lucero (Guardamar del Segura, Alicante) Quatrième champagne, 1984. Mélanges de la Casa de Velázquez, XXI: 393-404.

Aranegui, C.; Jodin, A.; Llobregat, E. A.; Rouillard, P.; Uroz, J. (1983): Fouilles du site ibérique de Cabezo Lucero (Guardamar del Segura, Alicante) Troisième champagne, 1982. Mélanges de la Casa de Velázquez, XIX: 487-496.

Atrián, P. (1961): Cerámica céltica del poblado de San Cristóbal (Mazaleón). Teruel, 26: 229-246.

Bea, D.; Diloli, J. (2005): Elements de representació durant la Primera Edat del Ferro al curs inferior de l'Ebre: el recinte del Turó del Calvari (Vilalba dels Arcs, Terra Alta). Revista d'Arqueologia de Ponent, 15: 179-198.

Bea, D.; Diloli, J; Garcia i Rubert, D.; Moreno, I.; Moret, P. (2012): Arquitectura de prestigio y aristocracias indígenas. Iberos del Ebro. Documenta, 25 ( M. C. Belarte, J. A., Benavente, L. Fatás, J. Diloli, P. Moret, J. Noguera, Eds.), Institut Català d'Arqueologia Clàssica. Tarragona: 51-70.

Belmonte, J. A. (1999): Las leyes del cielo. Temas de Hoy, Madrid.

Belmonte, J.A; Hoskin, M. (2002): Reflejo del Cosmos. Atlas de arqueoastronomía del Mediterráneo antiguo. Equipo Sirius, Madrid.

Blánquez Pérez, J. J. (1990): La formación del mundo ibérico en el sureste de la Meseta (estudio arqueológico de las necrópolis de la provincia de Albacete). Instituto de Estudios Albacentenses-CSIC, Albacete.

Bonet, H. (1995): El Tossal de Sant Miquel de Llíria. La antigua Edeta y su territorio. Servicio de Investigación Prehistórica, Diputación de Valencia, Valencia.

Bonet, H.; Mata, C. (1997): Lugares de culto edetanos. Propuesta de definición. Quaderns de Prehistòria i Arqueologia de Castelló, 18: 115-146.

Bonet, H.; Mata, C. (2009): El urbanismo ibérico en el área valenciana. El "oppidum” como centro de poder y reflejo del tejido social. Butlletí Arqueològic, 31: 107-144.

Bosch Gimpera, P. (1913-1914): Campanya arqueológica de l'Institut d'Estudis Catalans al limit de Catalunya i Aragó (Caseres, Calaceit y Massalió). Annuari de l'Institut d'Estudis Catalans, V: 819-838.

Bosch Gimpera, P. (1915-1920): Les investigacions de la cultura ibérica al Baix Aragó. Annuari de l'Institut d'Estudis Catalans, VI: 641-671.

Cohen, M. E. (1993): The Cultic Calendar of the Ancient Near East. CDL Press, Bethesda. 
Chapa Brunet, T.; Mayoral Herrera, V. (2007): Arqueología del trabajo. El ciclo de la vida en un poblado ibérico. Ediciones Akal, Madrid.

Chapa Brunet, T.; Pereira Sieso, J. (1992): La necrópolis de Castellones de Ceal (Hinojares, Jaén). Congreso de Arqueología Ibérica. Las Necrópolis. Serie Varia 1. Universidad Autónoma de Madrid, Madrid: 431-454.

Diloli, J.; Bea, D.; Sardà, S. (2018): El Turó del Calvari de Vilalba dels Arcs: L'arquitectura del poder a L'Ebre durant la protohistòria. Universitat Rovira i Virgili, Tarragona.

Duval, P. M.; Pinault, G. (1986): Recueil des inscriptions Gauloises (RIG) sous la direction de Paul-Marie Duval, vol. 3. Les Calendriers (Coligny, Villards d'Heria). Paris, CNRS.

Espejo Muriel, C. (1995): Grecia: sobre los ritos y las fiestas (2 ${ }^{a}$ edición corregida). Universidad de Granada, Granada.

Esteban, C. (2002): Elementos astronómicos en el mundo religioso y funerario ibérico, Trabajos de Prehistoria, 59 (2): 81-100. https://doi.org/10.3989/tp.2002.v59.i2.199

Esteban, C. (2013): Arqueoastronomía y religión ibérica. Congreso Internacional Santuarios iberos: territorio, ritualidad y memoria. El Santuario de la Cueva de La Lobera de Castellar (Jaén) 1912-2012 (C. Rísquez, C. Rueda, Eds.), Asociación para el desarrollo rural de la Comarca de El Condado, Jaén: 465-489.

Esteban, C. (2014): Orientación de las tumbas y astronomía en la necrópolis de la Angorrilla. La necrópolis de época tartésica de la Angorrilla (Alcalá del Río, Sevilla) (A. Fernández Flores, A. Rodríguez Azogue, M. Casado Ariza, E. Prados Pérez, Eds.), Universidad de Sevilla, Sevilla: 321-327.

Esteban, C. (2016): Equinoctial Markers in Protohistoric Iberian Sanctuaries Mediterranean Archaeology and Archaeometry, 16 (4): 297-304. https://doi.org/10.5281/zenodo. 220950.

Esteban, C. (2017): Lugares de culto y astronomía en Iberia y el Norte de África durante la protohistoria. Entre el cielo y la tierra: arqueoastronomía del mundo feniciopúnico. XXX Jornadas de arqueología fenicio-púnica (A. C. González-García, B. Costa, Eds.), Museu Arqueològic d'Eivissa i Formentera, Eivissa: 81-116.

Esteban, C.; Benítez de Lugo Enrich, L. (2016): Orientaciones astronómicas en el oppidum oretano del Cerro de las Cabezas (Valdepeñas, Ciudad Real). Trabajos de Prehistoria, 73 (2): 268-283. https://doi. org/10.3989/tp.2016.12173.

Esteban, C.; Espinosa Ruiz, A. (2018): El equinoccio en el ritual ibérico. El santuario de La Malladeta (La Vila Joiosa, Alicante). Archivo Español de Arqueología, 91: 265-278. https://doi.org/10.3989/aespa.091.018.013.

Esteban, C.; Moret, S. (2006): Ciclos de tiempo en la cultura ibérica: la orientación astronómica del Templo del Tossal de Sant Miquel de Llíria. Trabajos de Prehistoria, 63 (1): 167-178. https://doi.org/10.3989/ tp.2006.v63.i1.11.

Esteban, C.; Rísquez, C.; Rueda, C. (2014): Una hierofanía solar en el santuario ibérico de Castellar (Jaén). Archivo Español de Arqueología, 87: 91-107. https://doi.org/10.3989/aespa.087.014.006.

Fatás, L. (2004-2005): Un espacio diferencial en San Cristóbal de Mazaleón (Teruel): los materiales del espacio 2. Quaderns de prehistòria i arqueologia de Castelló, 24: 163-172.

Fatás, L. (2007): San Cristóbal de Mazaleón memoria de investigación y excavación (2004-2006). Saldvie: Estudios de prehistoria y arqueología, 7: 175-198.

Fatás, L. (2016): La Edad del Hierro en el valle del Matarraña (Teruel). Las investigaciones del Institut d'Estudis Catalans en el bajo Aragón. Caesaragusta, 85, Zaragoza.

Fernández Flores, A.; Prados Pérez, E.; Rodríguez Azogue, A. (2014): Catálogo de sepulturas. La necrópolis de época tartésica de la Angorrilla (Alcalá del Río, Sevilla) (A. Fernández Flores, A. Rodríguez Azogue, M. Casado Ariza, E. Prados Pérez, Eds.), Universidad de Sevilla, Sevilla: 85-249.

Fernández Flores, A.; Rodríguez Azogue, A. (2007): Vida y muerte en la Ilipa tartésica. Ilipa Antiqva. De la prehistoria a la época romana (E. Ferrer Albelda, A. Fernández Flores, J. L. Escacena Carrasco, A. Rodríguez Azogue, Eds.), Excmo. Ayuntamiento de Alcalá del Río, Alcalá del Río: 103-130.

García Cano, J. M. (1990): Notas sobre la necrópolis ibérica de Los Nietos. Verdolay, 2: 161-171.

García-Gelabert, M. P. (1999): Rituales funerarios en el mundo ibérico. Religión y magia en la antigüedad, Generalitat Valenciana, Valencia: 103-122.

García-Gelabert, M.P.; Blázquez, J.M. (1992): Las necrópolis oretanas de Cástulo. Paralelos con las necrópolis ibéricas del Sureste. Congreso de Arqueología Ibérica. Las Necrópolis. Serie Varia 1, Universidad Autónoma de Madrid, Madrid: 455-472. 
Molinos Molinos, M.; Chapa Brunet, T.; Ruíz Rodríguez, A.; Pereira Sieso, J.; Rísquez Cuenca, C.; Madrigal Belinchón, A.; Esteban Marfil, A.; Mayoral Herrera, V.; Llorente García, M. (1998): El santuario heroico de El Pajarillo, Huelma (Jaén). Universidad de Jaén, Junta de Andalucía y Excma. Diputación Provincial de Jaén, Jaén.

Moneo, T. (2003): Religio Iberica. Santuarios, ritos y divinidades (siglos VII-I a.C.). Real Academia de la Historia, Madrid.

Moneo, T.; Pérez, J.; Vélez, J. (2001): Un santuario de entrada ibérico en El Cerro de las Cabezas (Valdepeñas, Ciudad Real). Complutum, 12: 123-136.

Pérez Gutiérrez, M.; Bea Castaño, D.; Diloli Fons, J.; Sardà Seuma, S. (2016): Astronomy and the power: the singular building of Turó del Calvari (Vilalba dels Arcs, Tarragona). Astronomy and Power: How worlds are structured (M. A. Rapenglück, B. Rapppenglück, N. Campion, F. Silva, Eds.), Bar International Series, Oxford: 285-293.

Pérez Gutiérrez, M; Diloli Fons, J.; Bea Castaño, D.; Sardà Seuma, S. (2011): Astronomy, culture and landscape in the Early Iron Age in the Ebro Basin. Archaeoastronomy and Ethnoastronomy: Building Bridges between Cultures (C. L. N. Ruggles, Ed.), IAU Symposium no. 278, Cambridge University Press, Cambridge: 382-389.

Pérez Gutiérrez, M.; Ruiz Rodríguez, A.; Molinos Molinos, M. (2016). The Iberian Urban Sanctuary of Puente Tablas (Jaén, Spain). Mediterranean Archaeology and Archaeometry, 16 (4): 313-319. https:// doi.org/10.5281/zenodo.220952.

Rafel, N. (2003): Les necròpolis tumulàries de tipus baixaragonès: les campanyes de l'Institut d'Estudis Catalans al Matarranya. Monografies, 4, Museu d'Arqueologia de Catalunya, Barcelona.

Ramos Sainz, M. L. (1986): Estudio sobre el ritual funerario en las necrópolis fenicias y púnicas de la península ibérica. Ediciones de la Universidad Autónoma de Madrid, Madrid.

Rodríguez-Ariza, M. O.; Pérez Gutiérrez, M. (2013): El túmulo 20. Un espacio sagrado en la necrópolis ibérica de Tútugi. Congreso Internacional Santuarios iberos: territorio, ritualidad y memoria. El Santuario de la Cueva de La Lobera de Castellar (Jaén) 1912-2012 (C. Rísquez, C. Rueda, Eds.), Asociación para el desarrollo rural de la Comarca de El Condado, Jaén: 433-445.

Rouillard, P.; Espinosa, A.; Moratalla, J. (2014): Villajoyosa Antique (Alicante, Espagne). Territoire et topographie. Le sanctuaire de La Malladeta. Casa de Velázquez, Madrid.

Rubio, R. (1986): La necrópolis ibérica de la Albufereta de Alicante (Valencia, España). Serie arqueológica 11, Academia de Cultura Valenciana, Valencia.

Ruggles, C. L. N. (1997): Whose equinox?. Archaeoastronomy (Supplement to the Journal for the History of Astronomy), 22: 45-49.

Ruiz Rodríguez, A.; Molinos Molinos, M.; Fernández, R.; Pérez Gutiérrez, M.; Rueda, C. (2015): El Santuario de la Puerta del Sol. Jaén, tierra ibera. 40 Años de investigación y transferencia (A. Ruiz Rodríguez; M. Molinos Molinos, Coords.), Universidad de Jaén, Jaén: 93-106

Sanmartí-Grego, E. (1979): Les cultures protohistòriques del Matarranya: un estat de la qüestió. Fonaments 1: $121-149$.

Sardà, S. (2010): Pràctiques de consum ritual al curs inferior de l'Ebre (s. VII-VI ane). Comensalitat, ideologia i canvi social. Tesis Doctoral Inédita. Universidad Rovira i Virgili, Tarragona.

Sardà, S.; Fatás, L.; Graells, R. (2010): Prácticas rituales, comensalidad e ideología en un espacio de transición. Ámbitos diferenciales en la Terra Alta-Matarraña (s.VII-VI a.C.). Ritos y Mitos. VI Simposio sobre celtiberos (F. Burillo, Ed.), Centro de Estudios Celtibéricos de Segeda, Zaragoza: 45-56.

Thom, A. (1967): Megalithic Sites in Britain. Oxford University Press, Oxford.

Tomás, J. (1959): Elementos estables de los túmulos bajoaragoneses de cista excéntrica. Caesaraugusta, 13-14: 79-127.

Tomás, J. (1960): Elementos estables de los túmulos bajoaragoneses de cista excéntrica (Conclusión). Caesaraugusta, 15-16: 41-89.

Vallespí Pérez, E. (2001): Reconocimiento arqueológico del Bajo Aragón en el siglo XIX y primer tercio del XX: evocación de sus protagonistas. Spal, 10: 57-7.

Vives-Ferrándiz, J. (2005): Negociando encuentros: situaciones coloniales e intercambios en la costa oriental de la península ibérica (ss.VIII-VI a.C.). Cuadernos de Arqueología Mediterránea, 12, Barcelona. 